\title{
Electrochemical Behavior of Iodine on Nano Gold Doped in $\mathrm{H}_{2} \mathrm{TiO}_{3}$
}

\author{
Y. Z. Song ${ }^{*}$, X. L. Yuan' M.J.Yang, J.J. Ding, W.J. Lu, X.L.Hang
}

School of Chemistry \& Chemical Engineering, Huaiyin Normal University, Jiangsu Province Key Laboratory for Chemistry of Low-Dimensional Materials, Huai An 223300, People's Republic of China

*E-mail: songyuanzhi@126.com; songyuanzhi@sina.com

doi: $10.20964 / 2016.11 .19$

Received: 16 June 2016 / Accepted: 25 August 2016 / Published: 10 October 2016

In this paper the nano gold doped in $\mathrm{H}_{2} \mathrm{TiO}_{3}$ were prepared, and the electrochemical catalysis for iodine at the modified electrode was studied. It was demonstrated that when the $\mathrm{pH}$ is less than 9 , the $\mathrm{I}^{-}$ at the modified electrode can be oxidized to be $\mathrm{I}_{2}$ and then $\mathrm{IO}_{3}{ }^{-}$, and the reduction peaks of $\mathrm{I}_{2}$ and $\mathrm{IO}_{3}{ }^{-}$ at the modified electrode were also found; when the $\mathrm{pH}$ is more than 9 , the $\mathrm{I}^{-}$is oxidized to be $\mathrm{IO}_{3}{ }^{-}$ directly, and the reduction product of $\mathrm{IO}_{3}{ }^{-}$at the modified electrode is $\mathrm{I}^{-}$.

Keywords: nano gold, $\mathrm{H}_{2} \mathrm{TiO}_{3}$, iodine, catalysis

\section{$\underline{\text { FULL TEXT }}$}

(C) 2016 The Authors. Published by ESG (www.electrochemsci.org). This article is an open access article distributed under the terms and conditions of the Creative Commons Attribution license (http://creativecommons.org/licenses/by/4.0/). 